\title{
О ПОВЫШЕНИИ ПРИОРИТЕТА РАЗВИТИЯ ОБРАБАТЫВАЮЩЕЙ ПРОМЫШЛЕННОСТИ
}

\author{
Корнев А.К.
}

Исследуются способы дотирования производств обрабатьвающей промышленности. В условиях открытой рыночной экономики предлагается возврат к перераспределению природной ренты, как максимальному дотированию. Для этого необходимо преобразование существующих производств обрабатывающей промышленности в вертикально интегрированные межотраслевые корпорациии.

DOI: $10.20537 /$ mce2020econ01

Развитие отечественной экономики в постреформенный период сопровождается, как известно, деградацией и угасанием обрабатывающей промышленности: удельный вес ее в экономике постоянно снижается, объемы производства ее продукции уменьшаются. При этом объемы производства продукции каждой из пяти больших групп продукции обрабатывающей промышленности также значительно сократились. Это свидетельствует об общих причинах уменьшения производства продукции обрабатывающей промышленности и примерно равном воздействии этих причин на весь спектр разнообразной продукции.

Причины сокращения производства продукции обрабатывающей промышленности. Анализ динамики производства пяти групп продукции показывает, что происходит уменьшение выпуска продукции обрабатывающей промышленности в результате, прежде всего, воспроизводственных причин. Они сводятся к невозможности обновления и модернизации активной части основного капитала производств обрабатывающей промышленности на основе отечественной техники на достаточно высоком техническом уровне, как это предусматривалось в программах развития экономики. Одной из этих воспроизводственных причин является деградация качества первой группы ключевых производств инвестиционного машиностроения, в том числе их продукции, вовремя не исправленная на основе, как отечественных инвестиций, так и закупок импортной техники. Эти производства призваны постоянно 
поддерживать свой высокий технический уровень, чтобы обеспечить такой же уровень второй группе отраслевых производств инвестиционного машиностроения. Деградация производств сначала первой, а затем и второй группы не позволяет в приемлемом виде обновить и модернизировать производственный аппарат третьей группы производств обрабатывающей промышленности, выпускающих продукцию для дальнейшего производственного использования. Четвертую группу производств товаров народного потребления представляют те же отрасли обрабатывающей промышленности, что и третью группу, но дополнительно они включают гражданское машиностроение. Производственный аппарат четвертой группы производств также оказалось невозможно удовлетворительным образом обновить и модернизировать на основе поставок отечественной техники. Пятая группа производств технически сложных товаров длительного пользования создавалась индивидуальным образом с использованием конверсии оборонной промышленности, зарубежных закупок производств, отечественных передовых разработок, перепрофилирования и расширения производств. Провести обновление и модернизацию производственного аппарата этой группы производств оказалось крайне сложно в техническом отношении. Таким образом, деградация производств первой группы определила в конечном итоге деградацию производственного аппарата и других групп обрабатывающей промышленности, затем произошло снижение рентабельности ее продукции, банкротство и ликвидация предприятий.

Вместе с тем в рассматриваемый период происходило дополнительно, как явление, удорожание производимой продукции обрабатывающей промышленности. Оно приводило к снижению конкурентоспособности продукции, уменьшению объемов ее реализации, сокращению доходов от ее продажи, снижению рентабельности производства продукции, неспособности предприятий в финансовом отношении произвести обновление и модернизацию производственного аппарата, банкротствам и ликвидациям предприятий. Удорожание продукции обрабатывающей промышленности определяло банкротство и ликвидация всех типов предприятий, то есть таких, производственный аппарат, которых формировался как на основе отечественной техники, так и импортной. В результате удорожания отечественной технически сложной продукции длительного пользования, а также значительного роста качества зарубежной продукции в составе пятой группы произошла ее полная замена аналогичной импортной техникой. А продукция четвертой группы това- 
ры народного потребления характеризуется сравнительно постоянным спросом. Поэтому она производится более дешевым способом зарубежными производственно-технологическими цепочками, а последние одна-две операции (покраска, сборка) осуществляются на нашей территории с сохранением прежних брендов этой продукции.

Таким образом, деградация ключевых и отраслевых производств инвестиционного машиностроения, удорожание производимой продукции обрабатывающей промышленности, сокращение ее доходов, и тем самым невозможность осуществления необходимого объема импортных инвестиций, привели к деградации производственного аппарата ее предприятий, нехватке финансовых средств для его обновления и модернизации. В конечном итоге эти предприятия оказываются банкротами и ликвидируются. Банкротства и ликвидация предприятий обрабатывающей промышленности измеряются колоссальными величинами. Согласно расчетам В.Н. Симчеры, при веденным в статье Чуйкова А. [1], с 1991 г. по 2017 г. уничтожено 78 тыс. средних и крупных промышленных предприятий, при этом только с 2005 г. по 2015 г. - 35 тыс. (а потери промышленности во время Великой отечественной войны сравнимы - 32 тыс. предприятий, меньших по масштабу). Выпуск продукции в натуральном исчислении сократился в десятки раз. Примерно 10\% работающих в России предприятий находятся в предбанкротном состоянии. После кризиса 2014 г. ежемесячно банкротилось от 1000 до 1050 предприятий, то есть более 12000 предприятий ежегодно [2]. Причем, этот процесс ускоряется.

Создание государственного перераспределительного фонда с целью финансовой поддержки обрабатывающей промышленности в постреформенный период. В настоящее время существуют различные представления о причинах возникновения удорожания продукции обрабатывающей промышленности в постреформенный период. Так, реформаторы и их сторонники полагают, что банкротства и ликвидация предприятий обрабатывающей промышленности, созданных еще в советский период, происходят в связи с какими-то элементами их неэффективного функционирования. Например, старыми не конкурентоспособными технологиями основного или вспомогательного производства; некачественными фрагментами в производственно-технологических цепочках, требующими дополнительных затрат; отсутствием каких-либо новых агрегатов на замену выбывающим; использованием не лучших материалов в сооружениях, появление трещин и других внешних дефек- 
тов; прекращением поставок необходимых для производства сырья и материалов; изменением требований к качеству производимой продукции; плохими управленческими решениями.

В рамках этого подхода могут быть выделены многие десятки других подобных обстоятельств, которые, по мнению реформаторов, требуют дополнительных затрат на функционирование предприятий вместе с другими подобными обстоятельствами, возникшими раньше или позднее. Реформаторы полагают, что, с одной стороны, предприятия, созданные в советский период («советские») подвержены в ходе эксплуатации росту затрат на производимую продукцию, а с другой стороны, что банкротства и ликвидация предприятий обрабатывающей промышленности могут сами собой прекратиться. Кроме того, они заявляли, что главное для них заключается во владении и распоряжении нефтегазовыми ресурсами страны, а все необходимое, в том числе продукцию обрабатывающей промышленности, они приобретут на внешнем рынке. Поэтому они не создают не только долгосрочных, но и среднесрочных программ развития промышленности, в том числе и, в первую очередь, обрабатывающей. В то же время поддержка обрабатывающей промышленности, возникшая в сравнительно недавний период, может быть охарактеризована только как декоративная.

В декабре 2008 г. Правительственной комиссией по повышению устойчивости развития российской экономики был разработан перечень системообразующих организаций России. В него было включено 295 предприятий. В мае 2009 г. список был дополнен 9 единицами и составил 304 предприятия. В этом списке выделялись следующие отрасли экономики (в скобках количество позиций). Транспорт (30), энергетика (36), нефть и газ (11), угольная промышленность (6), связь (11), СМИ (7), металлургическая и добывающая промышленность (34), химическая и нефтехимическая промышленность (17), автомобильная промышленность (5), оборонно-промышленный комплекс (7), авиастроение (3), судостроение (13), двигателестроение (6), сельхозмашиностроение (3), энергетическое машиностроение и урановый цикл (5), ракетнокосмическая промышленность (19), радиоэлектронная промышленность (7), транспортное машиностроение (4), станкостроение (5), промышленность строительных материалов (7), лесопромышленный комплекс (5), аптечные сети (1), фармацевтическая промышленность (12), торговые сети (7), пищевая промышленность и агропромышленный комплекс (37), жилищное строительство (6), ювелирная промышленность (1), гознак (1). 
Совершенно очевидно, что в списке указано много предприятий, принадлежащих к обрабатывающей промышленности. Это свидетельствует о том, что руководство страны, с одной стороны, не исключает финансовую помощь предприятиям всех отраслей. А с другой стороны, финансовую помощь предприятиям обрабатывающей промышленности считает более важной, чем другим предприятиям. В списке удельный вес предприятий обрабатывающей промышленности оценивается как составляющий примерно три четверти от общей величины, а удельный вес других предприятий, соответственно, как одна четвертая. В сопроводительной информации Минэкономразвития России сообщается, что включение организации в Перечень не является гарантией предоставления государственной поддержки, равно как и отсутствие организации в Перечне не исключает возможности оказания государственной поддержки. В этом сообщении можно дополнительно увидеть и скрытое предложение торга за размеры финансовой поддержки.

В феврале 2015 г. утвержден новый Перечень системообразующих организаций. Он включает 197 организаций. Этот список включает не только предприятия обрабатывающей промышленности, но и других отраслей экономики. Уменьшение этого списка по сравнению с предшествующим связано, прежде всего, со значительным сокращением количества предприятий, представляющих оборонно-промышленный комплекс. Основа первого списка не сохранилась, поскольку предприятий, входящих в первый и второй списки, сравнительно немного. Их доля лишь немногим превосходит треть от общего количества предприятий второго списка.

Во втором списке удельный вес не обрабатывающих производств примерно в два раза меньше, чем в первом списке. Присутствие в этом списке торговых организаций связано, по-видимому, со сдерживанием роста цен на их продукцию и является элементом социальной политики для населения. Например, «Седьмой континент», Компания «М.Видео», «Дикси Групп», «Аптечная сеть 36.6», «Ашан». Но сюда включен и нефтегазовый сектор, в частности: «Газпром», «НК «Роснефть»», «НК «Русснефть»», «НГК «Славнефть»», «Сургутнефтегаз». Государственный перераспределительный фонд составил 1 трлн руб., а персональная сумма определяется 5 млрд руб. каждому из состава списка. Сумма в 1 трлн руб. явно недостаточна для этих целей.

Необходимо отметить, что в 2018 г. был составлен перечень стратегических предприятий и организаций, составивший 1131 единицу. В 
этом списке были выделены федеральные государственные предприятия в количестве 591 единица, 494 открытые акционерные общества, 46 иных предприятий и организаций. Таким образом, количество предприятий обрабатывающей промышленности, оказавшееся включенным во второй Перечень предприятий, составляет совсем малую величину от общего списка стратегических предприятий и организаций. То есть, чтобы поддержать только стратегические организации необходимо многократно увеличить перераспределительный фонд поддержки предприятий. Однако, кроме стратегических организаций имеются и другие в обрабатывающей промышленности, крайне важные для отечественной экономики и также нуждающиеся в финансовой поддержке государственных органов власти. Совместно все эти предприятия и организации определяют потребности в дополнительном, в десятки раз увеличении перераспределительного фонда. Такое увеличение фонда не может быть создано в рамках существующей экономики.

\section{Причины удорожания продукции обрабатывающей промыш-} ленности в постреформенный период. В результате радикальной реформы, как известно, была ликвидирована закрытая плановая экономика с государственной собственностью на предприятия, а вместо нее на основе приватизации предприятий была создана открытая рыночная экономика с либерализированными ценами. В новых условиях, созданных реформаторами, внутренние потоки продукции добывающей промышленности были мгновенно переориентированы на экспорт по более высоким мировым ценам. В то же время производства отечественной обрабатывающей промышленности оказались вынужденными приобретать продукцию добывающей промышленности по этим высоким экспортным ценам, которые лишают их производства дотаций и соответственно возможностей обновить производственный аппарат, а их продукцию ценовой конкурентоспособности, прежних объемов производства и доходов. Таким образом, реформаторы ликвидировали основы индустриального развития экономики. Эти обстоятельства даже не входили в их комментарии.

Удорожание продукции обрабатывающей промышленности, лишающее ее ценовой конкурентоспособности, является результатом деиндустриализации экономики. Удорожание этой продукции неизбежно приводит соответствующие предприятия, производящие эту продукцию, к банкротству и ликвидации. Непосредственными причинами удорожания рассматриваемой продукции являются изъятия с использованием 
ценового механизма природной ренты у предприятий обрабатывающей промышленности. Природная рента возвращается предприятиям добывающей промышленности и теперь у них она не изымается в пользу обрабатывающей промышленности. Предприятия обрабатывающей промышленности потеряли дотации и теперь не могут дешевле производить свою продукцию.

Последствия радиальной реформы для обрабатывающей и добывающей промышленности. Реформаторы в максимальной мере использовали доходы добывающей промышленности в своих личных целях. Наибольшие возможности в этом отношении возникли в нефтегазовой промышленности. В этих отраслях в постреформенный период времени произошли значительные изменения в практике заключения договоров. А именно: не использовались подрядчиками сервисные договора на каждую отдельную операцию производства продукции, сохраняющие государственную собственность на нее. Они приняты в качестве основных в других нефтедобывающих странах. А предпочтение отдавалось заключению лицензионных договоров, которые передают подрядчикам вместе с продукцией право собственности на нее и соответственно право ею распоряжения. Согласно расчетам вице-президента Российской академии экономических наук, экс-директора НИИ статистики Росстата Василия Симчеры и директора центра «Модернизация» Михаила Абрамова, которые провели специальное исследование по просьбе «Аргументов недели» и подготовили материал «О неиспользуемых резервах роста бюджета РФ» в 2018 г. в бюджет не поступило около 8 трлн рублей нефтегазовых доходов. А поступившая доля нефтегазовых доходов консолидированного бюджета в этом году составила около 9 трлн рублей. Убытки за 30 лет оказались больше 200 триллионов рублей [1]. Потери от последней отечественной войны, как известно, составили меньшую величину [3].

Например, несмотря на обещания «Газпрома» газифицировать все домохозяйства на территории России в течение 10 лет, которые неоднократно переносились на более поздние сроки, показатель газификации нашей страны остается на крайне низком уровне около 40\%. Он практически не возрастает. При этом колоссальные доходы «Газпрома» уберегаются, как и сверхдоходы других экспортеров сырьевых ресурсов, от перераспределения в пользу решения других важнейших народнохозяйственных задач. 


\section{Ограничения развития добывающей промышленности в}

настоящий период. В итоге утрат большого количества предприятий обрабатывающей промышленности возрастают предложения вложений в производства по добыче природных ресурсов, увеличивается конкуренция в эксплуатации природных ресурсов. А государственное участие в этой отрасли промышленности сокращено, и ее развитие становится чрезвычайно беспорядочным и противоречивым. Поэтому увеличивается нагрузка на сферу обитания в регионах, где производится добыча природных ресурсов, проживание в них оказывается даже опасным для здоровья населения.

В этих условиях даже максимально возможный прирост продукции добывающей промышленности не в состоянии заместить с использованием внешней торговли сравнительно небольшую часть продукции обрабатывающей промышленности. Дело в том, что производство продукции обрабатывающей промышленности характеризуется наличием длинных производственно-технологических цепочек. Каждое звено этой цепочки значительно увеличивает добавленную стоимость изделия, а цена конечного образца может быть очень большой, например, скоростного поезда, самолета, карьерного самосвала, океанского лайнера, гигантского телескопа, спутника. Даже стоимость современного инвалидного кресла или медицинского протеза могут быть очень большими. И этих изделий необходимо создать огромное количество для развития экономики страны. Например, нам необходимо вернуть малую авиацию, когда-то успешно летавшую буквально во все районные центры страны (а заодно улучшить работу метеорологической службы). А тогда нам нужны тысячи новых самолетов. Значительная часть этих изделий должна производиться отечественной промышленностью в соответствии с внутренним спросом на них (для себя), и с учетом внешнеэкономических потребностей (на экспорт). Сокращение производства продукции обрабатывающей промышленности приводит к некомпенсируемому ростом добывающей промышленности уменьшению валового национального продукта, к общей понижательной динамике экономики. Причем, эта тенденция может быть обнаружена, несмотря на попытки государственной власти явно преувеличивать долю услуг в отечественной экономике путем их досчета в статистических построениях. А физическая нехватка продукции обрабатывающей промышленности в регионах на практике временно устраняется, прежде всего, путем многократных ремонтов старых изделий, срок службы которых постоянно 
продлевается. Например, провинциальных автобусов, причем, не междугороднего, а внутригородского сообщения. Поэтому, нередко, причинами автомобильных катастроф становится старая техника, когда она отказывает, но не в месте последнего ремонта, а по причине возраста.

\section{Изменения в производстве продукции обрабатывающей про-} мышленности. В настоящее время осуществляется период, в котором разнообразие товарной массы обрабатывающей промышленности в нашей стране не увеличивается, скорее даже уменьшается. Его можно определить как свидетельство возможного уменьшения объемов продукции обрабатывающей промышленности до такой степени, когда доходы добывающей промышленности уже не способны с использованием внешней торговли компенсировать ее сокращение. В этих условиях уменьшения обрабатывающей промышленности невозможен рост реальных доходов населения. Наоборот, коренной перелом свидетельствует о наступлении периода, в котором ускоряется ликвидация предприятий обрабатывающей промышленности, происходит снижение реального уровня жизни населения, наряду с ростом цен на товары, возникает дефицит некоторых из них. Снижение экономических показателей может быть статистически скрыто за ростом услуг, объемы которых досчитываются, а их увеличение может интерпретироваться как улучшение жизни населения. Вместе с тем добиться реальной стабилизации экономики будет крайне сложно и даже невозможно, если в руководстве страны не изменится оценка результатов радикальной реформы. Особенно той ее части, в которой открытие экономики не сопровождалось созданием закрытых вертикально интегрированных структур, способствующих обеспечению необходимыми дотациями конечных производств этих структур и уберегающих производимую ими продукцию от удорожания, а сами производства от банкротства и ликвидации.

Тенденция ликвидации предприятий обрабатывающей промышленности в перспективный период может приобрести необратимый характер. Это может осуществиться в условиях, с одной стороны, сохранения внутренней ликвидационной тенденции и даже ее ускорения, а с другой стороны, усиления внешней санкционной деятельности против нашей страны с использованием и раздуванием конфликта против нее. Эта деятельность может быть синхронно организована и направлена на ее деиндустриализацию путем закрытия производств обрабатывающей промышленности, расположенных на территории нашей страны, но не являющихся в настоящее время собственностью нашего государства. 
Деиндустриализация экономики приведет к зависимости доходов населения, прежде всего, от развития добывающей промышленности. Но ее развитие ограничено экологическими обстоятельствами, зависит от цен на нее и спроса, и, пожалуй, не может быть значительным. Кроме того, значительная часть доходов добывающей промышленности принадлежит реформаторам, которые, как показала тридцатилетняя история взаимоотношений с ними, не намерены делиться своими доходами, даже если они оказываются временно неиспользуемыми остатками.

В этих условиях, по-видимому, не может быть сохранен прежний социальный порядок. Борьба за передел доходов добывающей промышленности, возможно, будет очень ожесточенной, с переменным успехом. Населению предстоит пережить не одно, а несколько снижений уровня жизни. Территория страны может не раз меняться, как в большую, так и в меньшую сторону. Подсобные участки снова будут востребованы, урожайность их может существенно возрасти в связи с изменением климата. Поэтому получат значительное развитие сельское хозяйство, различные промыслы, ремесла, торговля. Только в условиях возрождения обрабатывающей промышленности, по-видимому, сначала в южных регионах, возникнет тенденция устойчивого экономического развития страны, возможно, потерявшей некоторые территории.

Сценарий повышения роста производства продукции обрабатывающей промышленности. Этот сценарий может быть осуществлен в условиях адекватной оценки последствий современных и прогнозных потерь от банкротств и ликвидаций предприятий обрабатывающей промышленности. Он предполагает возвращение к дотационной поддержке предприятий обрабатывающей промышленности. Дотации будут основываться на использовании природной ренты, как и в советский период. Предполагается также использование новой структурной формы [4] закрытых вертикально интегрированных межотраслевых корпораций (ВИМК). В совокупности указанные обстоятельства позволят укрепить производственную базу обрабатывающей промышленности, создать рост производства ее продукции, произвести реиндустриализацию экономики [5].

Сценарий предполагает создание десятков закрытых ВИМК, которые позволят минимизировать потери от открытия экономики. В этих ВИМК должны быть нерыночные цены, а на продукцию добывающей промышленности в производственно-технологической цепочке установлены низкие цены, позволяющие перераспределять природную ренту в пользу конечных обрабатывающих производств. Современное за- 
конодательство делает возможным при строительстве начальных звеньев производственно-технологической цепочки корпорации выделять конкретные производства добывающей промышленности с природной рентой в составе цены их продукции. В этом случае добывающие производства передаются в собственность и распоряжение корпораций, и цена их продукции снижается в соответствии с договоренностями. В то же время недостающие для производственно-технологической цепочки звенья могут быть приобретены путем закупки с использованием внешней торговли, либо конверсии оборонных предприятий. Количество ВИМК должно постоянно увеличиваться, только в этом состоит возможность успешного развития обрабатывающей промышленности [6]. Для увеличения количества ВИМК некоторые производства необходимо разделить на несколько частей, чтобы их использовать одновременно в нескольких корпорациях.

При создании ВИМК необходимо исходить как из желаемого, так и из возможного. Возможными являются такие наборы производств, которые могут легко образовать новые вертикально интегрированные структуры. В настоящее время имеются наборы предприятий и обстоятельства для создания корпораций, которые выпускают, например, продукцию ключевых производств (ядра инвестиционного машиностроения). Среди них: станкостроение, кузнечнопрессовые машины, электротехническая, подъемно-транспортная, энергетическая, электронная промышленность, приборостроение. Это первая группа обрабатывающей промышленности. Создание хотя бы 1-5 ВИМК в этой сфере было бы успешным решением, но возможно и создание большего их количества, если придет осознание необходимости этой целевой установки. Любое увеличение этой группы должно приветствоваться, поскольку наблюдается буквально ее развал, особенно станкостроения, приборостроения, электронной промышленности. Появление даже минимального количества ВИМК способно поддержать эту группу в целом и особенно производителей выбранной продукции. Группа конечных производств призвана обновить и модернизировать производственный аппарат и ключевых, и отраслевых производств инвестиционного машиностроения. В то же время остальная часть таких ВИМК, включая добывающие, инфраструктурные и обрабатывающие производства, определяет ценовую конкурентоспособность конечной продукции, обновление и модернизацию используемого производственного аппарата. 
Продукция отраслевых производств инвестиционного машиностроения, как вторая группа обрабатывающей промышленности, также является возможной целью при формировании новых ВИМК. Ввод в действие примерно десятка дополнительных ВИМК являлся бы большой удачей. Поскольку производственный аппарат ключевых производств физически изношен, морально устарел, то эти производства необходимо обновить в результате импортных закупок, а затем уже обновить и конечные производства отраслей инвестиционного машиностроения.

Статистически малый результат покажут, видимо, объемы производства технологического оборудования для многих видов продукции обрабатывающей промышленности. В том числе легкой, пищевой, бумагоделательной, лесотранспортной, стекольной, полиграфической промышленности. А также для предприятий торговли, общественного питания и пищеблоков, прачечных, химической чистки одежды. В значимых объемах могут не сохраниться производства строительнодорожного машиностроения, промышленности средств связи, оборудования для литейного производства, для промышленности строительных материалов. Практически полностью прекратится производство противопожарного оборудования, абразивных и алмазных изделий, троллейбусов, санитарно-технического оборудования, роботов и инструмента, кабельной продукции.

Вместе с тем в перспективный период могут сохраниться производство оборудования для металлургической и топливной промышленности, сельскохозяйственное машиностроение, производство насоснокомпрессорного оборудования, железнодорожное машиностроение. Производства этой группы могут иметь финансовую поддержку. В этой группе продукции могут быть созданы 3-5 и даже больше ВИМК. Другой перспективной группой, также способной получать финансовую поддержку, являются производства: автомобилестроения, тракторного машиностроения, химического оборудования, металлоконструкций, нестандартизированного оборудования. В этой группе также могут быть образованы 3-5 ВИМК, крайне важных для обрабатывающей промышленности.

В составе других отраслей обрабатывающей промышленности необходимо выделение производств продукции, предназначенных для дальнейшего производственного использования. Эти производства составляют третью группу (после двух, связанных с инвестиционным машиностроением). В ее составе нефтеперерабатывающая, легкая, химическая и нефтехимическая, деревообрабатывающая и целлюлозно- 
бумажная, стекольная, фарфорово-фаянсовая, медицинская, полиграфическая промышленность, а также строительных конструкций и деталей. В эту группу включается также производство продукции перерабатывающей промышленности, направляемая в дальнейшее производственное использование. А именно: пищевая, микробиологическая, мукомольно-крупяная, и комбикормовая промышленность. В прогнозный период может не сохраниться производство продукции легкой, фарфорово-фаянсовой, микробиологической и комбикормовой промышленности. Но, несмотря на это, в группе могут быть созданы до десяти ВИМК и даже, в лучших обстоятельствах, гораздо больше.

Четвертая группа обрабатывающей промышленности почти совпадает отраслевым составом с третьей группой (в четвертой группе дополнительно выделены предприятия и объединения машиностроения), но существенно различается произведенной продукцией, поскольку четвертая группа производит товары народного потребления. По-видимому, товары народного потребления должны производить только ВИМК четвертой группы. В этом случае их может быть примерно 10-12 единиц.

Пятую группу обрабатывающей промышленности составляют технически сложные товары длительного пользования. Отечественные товары в постсоветский период были почти полностью заменены на соответствующие товары зарубежного производства. Разнообразие и сложность этих товаров постоянно увеличиваются. Кроме того, эта группа продукции постоянно пополняется за счет усложнения товаров народного потребления. Например, одежда с определенными свойствами, игровая аппаратура, современные инвалидные коляски, летательные аппараты, компьютеры и многие другие.

В нашей стране в настоящее время практически не производятся изделия, ранее выпускавшиеся: мотоциклы, в том числе с колясками, мотороллеры, стиральные машины, телевизоры, легковые автомобили отечественных марок, холодильники и морозильники, электропылесосы, швейные машинки, фотоаппараты и многие другие. В то же время иногда можно увидеть потребителей, которые с удовольствием до сих пор владеют этой техникой и сами поддерживают ее технический уровень, считают это простым делом. А ведь прошло много лет, и с учетом полной истории развития техники можно было бы производить еще лучшие ее образцы. Отчасти это оправдывается утратой лицензий на производство своей продукции, которые произошли после приватизации производств и их распродажи вместе с лицензиями на производство в США, 
Китай, Польшу и другие страны. Но все-таки мы могли бы за это время в судебном порядке кое-что вернуть, например, легкомоторные самолеты из Польши. Производство технически сложных товаров народного потребления необходимо, безусловно, восстановить в нашей стране, может быть, маленькими частями. Для создания этих производств необходимо использовать ВИМК.

\title{
СПИСОК ЛИТЕРАТУРЫ
}

1. Чуйков А. Этот стон у нас «деньги» зовется. Аргумент цифр от Василия Симчеры // Аргументы недели. 20-26 ноября 2019 г. № 45 (689).

2. Чуйков A. Россия - отстать навсегда? Мытари не плачут, мытари поют // Аргументы недели. 15-21 января 2020 г. № 1 (695).

3. Симчера В., Абрамов М. «Новая нефть» или нефтяной бюджет по-новому? // Завтра. Декабрь, 2019 г. № 49 (1356).

4. Кондратьева Т.С. Американская промышленность в 80-е годы: проблемы структурной перестройки / Реферативный сборник. Институт научной информации по общественным наукам АН СССР, Москва, 1987.

5. Корнев А. Возможности роста отечественной экономики на основе ее реиндустриализации // Экономист. 2018. № 7.

6. Корнев А.К., Максимичова С.И. О повышении конкурентоспособности действующих производств обрабатывающей промышленности // Проблемы прогнозирования. 2019. № 6 (177). С. 83-94.

\section{ON THE BOOSTING OF THE PRIORITY OF THE MANUFACTURING INDUSTRY DEVELOPMENT}

\begin{abstract}
Kornev A.K.
Ways of subsidizing of manufacturing industry enterprises is analyzed. Under the conditions of open market economy returning to the natural resource royalty is considered as the highest possible subsidy. That could be maintained by the transformation of existing manufacturing enterprises into vertically integrated interindustrial corporations.
\end{abstract}

